\title{
Currents in the overhead transmission line lighting wire in case of single-phase short circuit
}

\author{
Kirill Zimin ${ }^{1}$, Nina Rubtsova ${ }^{2}$, Vladimir Ryabchenko ${ }^{1 *}$, Andrey Tokarskskiy ${ }^{1}$ \\ ${ }^{1}$ Joint-Stock Company "Research and Development Center of the Federal Grid Company of Unified Energy System", Kashirskoe shosse, \\ 22, bld.3, Moscow, Russia \\ ${ }^{2}$ Federal State Budgetary Scientific Institution “Izmerov Research Institute of Occupational Health”, prospect Budennogo,31, \\ Moscow, Russia
}

\begin{abstract}
The algorithms for currents induced in a grounded lightning wire (LW) with single-phase short circuit (SC) calculation are considered. It is shown that the method of short-circuit current and current in LW simultaneous determination gives more correct results for the assessment of LW thermal resistance.
\end{abstract}

\section{Introduction}

At the present time overhead transmission lines (OTL) are equipped with lighting wires (LW) containing fiberoptic communication channels (FOLW). FOLW technologically are grounded through even OTL tower by grounding device. In case of single phase short circuit (SPhSC) the damaged OTL phase current magnetic field induces the current in FOLW. This current magnitude should not be more than permissible thermal resistance.

\section{OTL and FOLW parameters}

Current induced in FOLW value determine on example of $200 \mathrm{kV}$ double-circuit OTL placed on intermediate tower of Itph220-2+5 brand as shown in Figure 1.

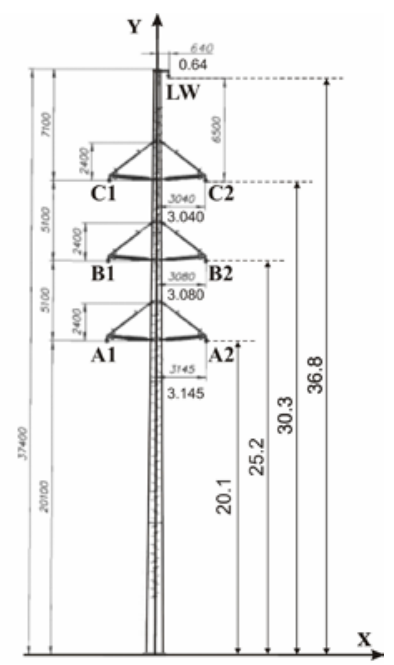

Fig. 1. $220 \mathrm{kV}$ double-circuit OTL on intermediate tower.
OTL phases made by one wire of AC-400/51 brand with $0.01375 \mathrm{~m}$ radius, lighting wire - by FOLW wire.

Phases wires and LW suspention heights are: $\mathrm{h}_{\mathrm{A}}=20.1$ $\mathrm{m}, \mathrm{h}_{\mathrm{B}}=25.2 \mathrm{~m}, \mathrm{~h}_{\mathrm{C}}=30.3 \mathrm{~m}$ and $\mathrm{h}_{\mathrm{LW}}=36.8 \mathrm{~m}$. Phases wires and LW SAG arrows are: $\mathrm{f}_{\mathrm{ph}}=10.1 \mathrm{~m}, \mathrm{f}_{\mathrm{LW}}=8.786 \mathrm{~m}$.

Phases wires and $\mathrm{LW}$ equivalent heights are $: \mathrm{h}_{\mathrm{AE}}=13.37$ $\mathrm{m}, \mathrm{h}_{\mathrm{BE}}=18.47 \mathrm{~m}, \mathrm{~h}_{\mathrm{CE}}=23.57 \mathrm{~m}$ and $\mathrm{h}_{\mathrm{LWE}}=30.94 \mathrm{~m}$.

220 кB OTL with $46.956 \mathrm{~km}$ length and $326.75 \mathrm{~m}$ span length is made without transpositions. Network resistance from substation 1 (S1) side is $\mathrm{Z}_{\mathrm{S} 1}=0.932+\mathrm{j} 8.455 \mathrm{Om}$, and from $\mathrm{S} 2$ side is $\mathrm{Z}_{\mathrm{S} 2}=0.841+\mathrm{j} 5.796 \mathrm{Om}$.

There were chosen the following brands of wires for currents induced in FOLW in case of SPhSC: FOLW-sh1-24(G.652)-18.7/93, FOLW-sh-1-16(G.652)-14.7/61, FOLW-sh-1-24(G.652)-13.1/54 and FOLW(G.652)12/94. Table 1 shows the values: $r_{\mathrm{wLW}}(\mathrm{mm})$-nominal radius; $\mathrm{R}_{\mathrm{LW} 0}(\mathrm{Om} / \mathrm{km})$ - resistivity, and $\mathrm{I}_{\mathrm{SCLW}}(\mathrm{kA})$ - SC permissible current by thermal resistance for $t$ (sec) permissible duration $-\mathrm{I}_{\mathrm{SCLW}} / \mathrm{t}(\mathrm{kA} / \mathrm{s})$ for each of FOLW chosen types.

Table 1. Chosen FOLW types $r_{\mathrm{wLW}}, \mathrm{R}_{\mathrm{LW} 0}$ and $\mathrm{I}_{\mathrm{SCLW}} / \mathrm{t}$ values

\begin{tabular}{|c|c|c|c|}
\hline FOLW brand & $\begin{array}{c}r_{\mathrm{wLW}}, \\
\mathrm{mm}\end{array}$ & $\begin{array}{c}\mathrm{R}_{\mathrm{LW}}, \\
\mathrm{Om} / \mathrm{km}\end{array}$ & $\mathrm{I}_{\mathrm{SCLW}} / \mathrm{t}, \mathrm{kA} / \mathrm{s}$ \\
\hline $\begin{array}{c}\text { FOLW-sh-1-24(G.652)- } \\
18.7 / 93\end{array}$ & 9.35 & 0.200 & $18.7 / 1.0$ \\
\hline $\begin{array}{c}\text { FOLW-sh-1-16(G.652)- } \\
14.7 / 61\end{array}$ & 7.35 & 0.329 & $\begin{array}{c}11.5 / 1.0 ; \\
15.0 / 0.59\end{array}$ \\
\hline $\begin{array}{c}\text { FOLW-sh-1-24(G.652)- } \\
13.1 / 54\end{array}$ & 6.55 & 0.443 & $8.9 / 1.0$ \\
\hline $\begin{array}{c}\text { FOLW-c-1-24(G.652)- } \\
12 / 94\end{array}$ & 6.00 & 1.116 & $5.6 / 1.0$ \\
\hline
\end{tabular}

Wire intrinsic specific inductive resistance $\left(\underline{Z}_{\mathrm{LW0}}\right)$ as well as mutual specific inductance resistance between LW and $k$ phase $\left(\underline{Z}_{\mathrm{Wk} 0}\right)$ taking into account 
ground specific resistance are calculated by full Carson’ expressions [1, 2]:

$$
\begin{aligned}
& \underline{Z}_{\mathrm{LW} 0}=\frac{j \omega \mu_{0}}{2 \pi \cdot 10^{-3}}\left(\ln \frac{\sqrt{2} \delta_{e}}{r_{\mathrm{wLW}}}-j \frac{\pi}{4}+\frac{4}{3} \frac{h_{\mathrm{LWE}}}{\delta_{e}}(1+j)-0,0772\right) \\
&, \mathrm{Ohm} / \mathrm{km}, \\
& \underline{Z}_{\mathrm{W} k 0}= \frac{j \omega \mu_{0}}{2 \pi \cdot 10^{-3}} \times \\
& \times\left[\ln \frac{\sqrt{2} \delta_{e}}{\left.\sqrt{a^{2}+\left(h_{\mathrm{kE}}-h_{\mathrm{LWE}}\right)^{2}}-j \frac{\pi}{4}+\frac{2}{3} \frac{h_{\mathrm{LWE}}+h_{\mathrm{kE}}}{\delta_{e}}(1+j)-0,0772\right],}\right.
\end{aligned}
$$

$\mathrm{Ohm} / \mathrm{km}$.

where $\omega=2 \pi f$ - angular frequency, $f=50 \mathrm{~Hz} ; \mu_{0}=4 \pi \cdot 10^{-7}$ $\mathrm{H} / \mathrm{m}$ - permeability of vacuum; $r_{\mathrm{wLW}}-\mathrm{LW}$ wire radius, $\mathrm{m}$; $a=\left|x_{k \mathrm{E}}-x_{\mathrm{LWE}}\right|$ - distance along the $x$ axis between $k$ phase wire and LW wire, m; $h_{\text {вЕ }}$ и $h_{\mathrm{LWE}}-k$ phase wire and LW wire equivalent heights, $\mathrm{m} ; \delta_{e}=\sqrt{2 \rho_{e} / \omega \mu_{0}}-$ penetration depth, $\mathrm{m} ; \rho_{3}$ - earth resistivity, Ohm·m.

Electromotive force $\mathbf{E}_{\mathrm{wk}}$, induced in LW wire to the span length $l_{\mathrm{sp}}(\mathrm{km})$ by $220 \mathrm{kV}$ OTL $k$ phase $\mathbf{I}_{k}$ current magnetic field is calculated by expression [2]:

$$
\begin{aligned}
\mathbf{E}_{\mathrm{Wk}} & =-\underline{Z}_{\mathrm{Wk}} \mathbf{I}_{k} l_{\mathrm{sp}}=-\frac{j \omega \mu_{0} \mathbf{I}_{k} l_{\mathrm{sp}}}{2 \pi \cdot 10^{-3}} \times \\
& \times\left[\ln \frac{\sqrt{2} \delta_{e}}{\sqrt{a^{2}+\left(h_{k \mathrm{E}}-h_{\mathrm{LWE}}\right)^{2}}}-j \frac{\pi}{4}+\frac{2}{3} \frac{h_{k \mathrm{E}}+h_{\mathrm{LWE}}}{\delta_{e}}(1+j)-0,0772\right], \quad \mathrm{V} .
\end{aligned}
$$

\section{$3220 \mathrm{kV}$ OTL operating in the no-load operation mode SPhSC currents}

SC leed to the arc emission between OTL damaged phase and the earth (grounded object), with $\mathrm{R}_{\mathrm{A}}$ arc resistance. $R_{A}$ value for $220 \mathrm{kV}$ OTL under $15 \mathrm{kA} \mathrm{SC}$ current is determined by lines in [3] and is: $R_{A}=0.42$ Ohm.

Consider the option when OTL operationg mode is no-load operation (NLO) with the connection of one side to the busbar source, and on the other - with the disconnection of all phases from the busbar. There were calculated SPhSC currents at different distances from S1 and S2 by use computer program «EMPVL», «OTL EMF»[4] computer program later modification. In case of equal distances from S1 with $\mathrm{Z}_{\mathrm{S} 1}$ and $\mathrm{S} 2$ with $\mathrm{Z}_{\mathrm{S} 2}$ the modules of the SPhSC current values powered by S2 are higher than modules powered by S1 because $\mathrm{Z}_{\mathrm{S} 1}>\mathrm{Z}_{\mathrm{S} 2}$. When calculating the currents induced in LW should focus on high SPhSC currents, i.e. the currents powered by S2.

Figure 2 shows the lines of phase C2 (nearest to LW phase) SPhSC current module distribution along to 220 $\mathrm{kV}$ OTL for SPhSC distances 0.5, 5, 10 and $30 \mathrm{~km}$ from S2. SPhSC current module decrease with SC place distance from S2.

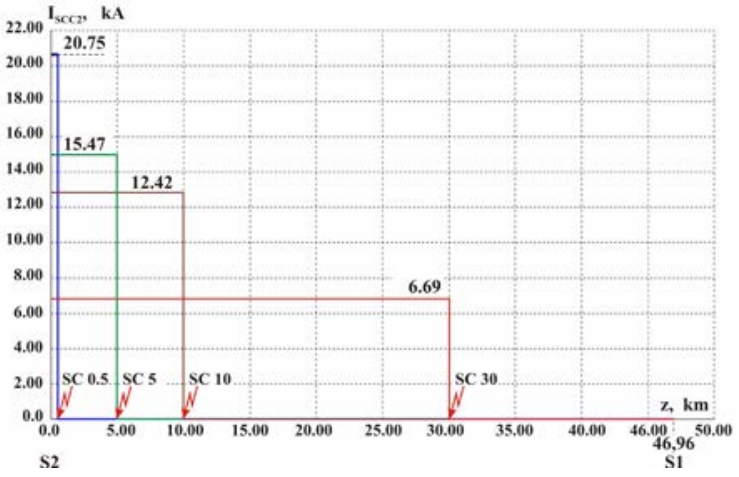

Fig. 2. Distribution along $220 \mathrm{kV}$ OTL phase C2 SPhSC current module for SPhSC 0.5, 5, 10 and $30 \mathrm{~km}$ distances from S2.

\section{Currents induced in LW for case of $220 \mathrm{kV}$ OTL SPhSC in the no-load mode}

Currents induced in double-circuit $220 \mathrm{kV}$ OTL LW calculate for FOLW-sh-1-24(G.652)-18.7/93 wire with $r_{\mathrm{wLW}}=0.00935 \mathrm{~m}$ and $\mathrm{R}_{\mathrm{W} 0}=0.20 \mathrm{Ohm} / \mathrm{km}$ under $\mathrm{SPhSC}$ $l_{\mathrm{K} 32}=0.5 \mathrm{~km}$ distance from S2.

For $\rho_{3}=100 \mathrm{Ohm} \cdot \mathrm{m}$ from (1) we obtain $\underline{Z}_{\mathrm{Lw} 0}=$ $0.04571+\mathrm{j} 0.7268 \mathrm{Ohm} / \mathrm{km}$. Then the specific activeinductive resistance of wire [5], located above the ground, $\underline{Z}_{\mathrm{W} 0}=\mathrm{R}_{\mathrm{T} 0}+\mathrm{j} \operatorname{Im}\left[\underline{Z}_{\mathrm{LW} 0}\right]=0.20+\mathrm{j} 0.7268$ $\mathrm{Ohm} / \mathrm{km}$, and the specific active resistance of the wire from losses in the ground $Z_{\mathrm{e} 0}=\operatorname{Re}\left[\underline{Z}_{\mathrm{LW} 0}\right]=0.04571$ $\mathrm{Ohm} / \mathrm{km}$. Wire resistance and losses in the ground (earth) at span length $l_{\mathrm{sp}}=0.32675 \mathrm{~km}$ are:

$$
\begin{aligned}
& \underline{Z}_{\mathrm{W}}=\underline{Z}_{\mathrm{w} 0} l_{\mathrm{sp}}=0.0654+\mathrm{j} 0.2375 \mathrm{Ohm} ; \\
& Z_{\mathrm{e}}=Z_{\mathrm{e} 0} l_{\mathrm{sp}}=0.0149 \mathrm{Ohm} .
\end{aligned}
$$

For $\mathbf{I}_{\mathrm{SCC} 2}=20.75 \angle 41.8^{\circ} \mathrm{kA} \mathrm{C} 2$ phase SPhSC current electromotive force $\mathbf{E}_{\mathrm{WC2}}$, this current induced in LW calculate by expression (3): $\mathbf{E}_{\mathrm{WC2}}=2,085.6 \angle-56.8^{\circ} \mathrm{V}$.

Figure3 shows the scheme of induced current calculation in $\mathrm{LW}$ under SPhSC at $l_{\mathrm{SC} 2}=0.5 \mathrm{~km}$ distance from S2.

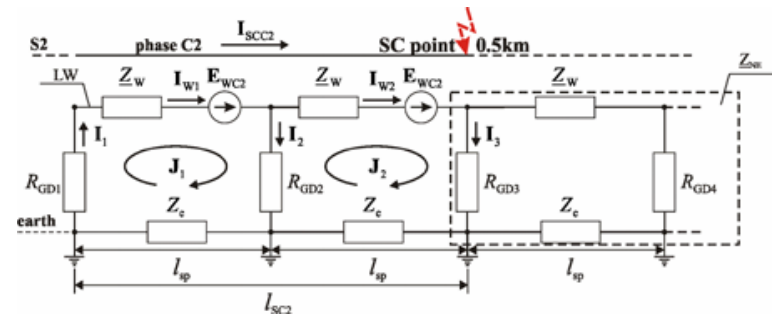

Fig. 3. Scheme of the current calculation in LW under SPhSC at $l_{\mathrm{SC} 2}=0.5 \mathrm{~km}$ distance from S2.

In case of SPhSC distance $l_{\mathrm{SC} 2}=0.5 \mathrm{~km}$ from S2 SPhSC current $\mathbf{I}_{\mathrm{SCC} 2}$ affect to the first two spans of LW, grounded on each tower $i$ by means of grounding device (GD) resistance $R_{\mathrm{GDi}}$. The rest spans are a sequence of passive double-poles, rolling the input resistance of which from the end of the OTL to the end of its second span, we obtain the resulting resistance $\underline{Z}_{\mathrm{NE}}$. 
We write a system of equations by the method of contour currents for scheme shown in Fiure 3:

$$
\left.\begin{array}{l}
\mathbf{J}_{1}\left(\underline{Z}_{\mathrm{W}}+Z_{e}+R_{\mathrm{GD} 1}+R_{\mathrm{GD} 2}\right)-\mathbf{J}_{2} R_{\mathrm{GD} 2}=\mathbf{E}_{\mathrm{WC} 2} ; \\
-\mathbf{J}_{1} R_{\mathrm{GD} 2}+\mathbf{J}_{2}\left(\underline{Z}_{\mathrm{W}}+Z_{e}+R_{\mathrm{GD} 2}+\underline{Z}_{\mathrm{NE}}\right)=\mathbf{E}_{\mathrm{WC} 2} \cdot
\end{array}\right\}
$$

Resistansce $Z_{\mathrm{NE}}$ value calculate. At fig. 4 there is shown the sequence of LW contours without electromotive force $\mathbf{E}_{\mathrm{WC2}}$.

$\underline{Z}_{\mathrm{N}}$ value as result of the first packaging of $\underline{Z}_{\mathrm{NN}}=\underline{Z}_{\mathrm{W}}+Z_{e}+R_{\mathrm{GDN}}$ passive double-pole input resistance and $R_{\mathrm{GDN}-1}$ resistance calculate by equation: $\underline{Z}_{\mathrm{N}}=\left(\underline{Z}_{\mathrm{NN}} R_{\mathrm{GDN}-1}\right) /\left(\underline{Z}_{\mathrm{NN}}+R_{\mathrm{GDN}-1}\right)$.

The second packaging of input resistance $\underline{Z}_{\mathrm{NN}-1}=\underline{Z}_{\mathrm{W}}+Z_{e}+\underline{Z}_{\mathrm{N}}$ and resistance $R_{\mathrm{GDN}-2}$ is carried out by equation: $\underline{Z}_{\mathrm{N}-1}=\left(\underline{Z}_{\mathrm{NN}-1} R_{\mathrm{GDN}-2}\right) /\left(\underline{Z}_{\mathrm{NN}-1}+R_{\mathrm{GDN}-2}\right)$ etc. until the end of $2^{\text {nd }}$ span.

Figure 4 scheme: $R_{\mathrm{GDN}-\mathrm{i}}=10 \mathrm{Ohm} ; R_{\mathrm{GDN}}=0.5 \mathrm{Ohm}$ in case of LW is grounded by GD last time in $\mathrm{S}$, and $R_{\mathrm{GDN}}=10 \mathrm{Ohm}$ in case of LW grouning by GD OTL tower.

After 50 packaging (16.34 km from S1 and $30.32 \mathrm{~km}$ from S2) resistance $\underline{Z}_{\mathrm{N}-\mathrm{i}}$ ceases to change in thousandths of the real and imaginary parts, as both for $R_{\mathrm{GDN}}=0.5$ Ohm, and for $R_{\mathrm{GDN}}=10 \mathrm{Ohm}$, and $\underline{Z}_{\mathrm{NE}}=\underline{Z}_{\mathrm{N}-50}=1.245$ + j0.809 Ohm.

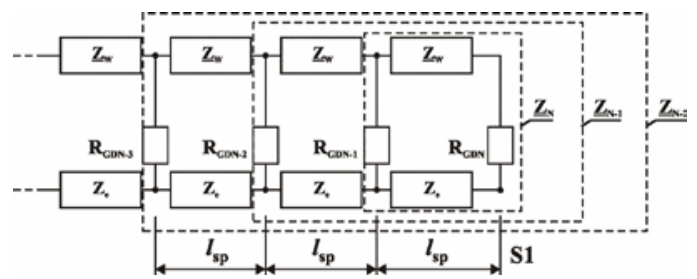

Fig. 4. The sequence of LW contours without electromotive force $\mathbf{E}_{\mathrm{WC} 2}$.

Initial data for the equations of system (4):

$$
\begin{aligned}
& \underline{Z}_{\mathrm{W}}+Z_{e}+R_{\mathrm{GD} 1}+R_{\mathrm{GD} 2}=10.580+\mathrm{j} 0.2375 \mathrm{Ohm} ; \\
& \underline{Z}_{\mathrm{W}}+Z_{e}+R_{\mathrm{GD} 2}+\underline{Z}_{\mathrm{NE}}=11.334+\mathrm{j} 1.0465 \mathrm{Ohm} ; \\
& R_{\mathrm{GD} 2}=10 \mathrm{Ohm} ; \quad \mathbf{E}_{\mathrm{WC} 2}=2,085.6 \angle-56,8^{\circ} \mathrm{V} .
\end{aligned}
$$

Current values in LW calculate by system of equations (4) solving:

$$
\begin{aligned}
& \mathbf{I}_{\mathrm{W} 1}=\mathbf{J}_{1}=1,855.3 \angle-89^{\circ} \mathrm{A}, \\
& \mathbf{I}_{\mathrm{W} 2}=\mathbf{J}_{2}=1,787.6 \angle-91^{\circ} \mathrm{A} .
\end{aligned}
$$

Electromotive forces $\mathbf{E}_{\mathrm{wB} 2}$ и $\mathbf{E}_{\mathrm{WA} 2}$, induced by B2 and A2 phases SPhSC currents $\mathbf{I}_{\mathrm{SCв} 2}=20.75 \angle 162.3^{\circ} \mathrm{kA}$ и $\mathbf{I}_{\mathrm{SCA} 2}=20.75 \angle-77.5^{\circ} \mathrm{kA}$, calculated by equation (3) are $\mathbf{E}_{\mathrm{WB} 2}=1,876.0 \angle 59^{\circ} \mathrm{V}$ and $\mathbf{E}_{\mathrm{WA} 2}=1,734.2 \angle-178^{\circ} \mathrm{V}$, that is low than $\mathbf{E}_{\mathrm{wC} 2}=2,085.6 \angle-56.8^{\circ} \mathrm{V}$. Therefore the currents in LW under phases B2 and A2 SPhSC are low by current module than current in LW under closer to LW phase C2 SPhSC.

Currents induced for chosen FOLW types are carried out under phase C2 SPhSC at $l_{\mathrm{SC} 2}=0.5,5$ and $10 \mathrm{~km}$ distance from S2. For example, consider phase C2 220 kV OTL SPhSC with FOLW-sh-1-24(G.652)-18.7/93 following at $l_{\mathrm{SC} 2}=5 \mathrm{~km}$ distance (see Figure 5).

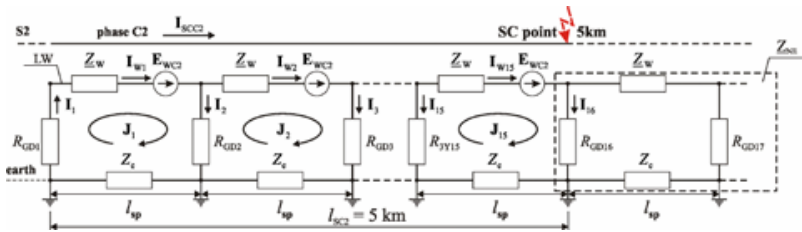

Fig. 5. The scheme of current in LW calculation under SPhSC at $l_{\mathrm{SC} 2}=5 \mathrm{~km}$ distance from S2.

$\mathbf{I}_{\mathrm{SCC} 2}=15.74 \angle 39.1^{\circ} \mathrm{kA}$ current applies to $15 \mathrm{LW}$ spans from S2 side, and in the each span induces electromotive force $\mathbf{E}_{\mathrm{wC2}}=1,582.1 \angle-59.5^{\circ} \mathrm{V}$ according to equation (3). A system of equations write by the method of contour currents:

$$
\begin{aligned}
& \mathbf{J}_{1}\left(\underline{Z}_{\mathrm{W}}+Z_{e}+R_{\mathrm{GD} \Pi \mathrm{C}}+R_{\mathrm{GD}}\right)-\mathbf{J}_{2} R_{\mathrm{GD}}=\mathbf{E}_{\mathrm{WC} 2} ; \\
& -\mathbf{J}_{1} R_{\mathrm{GD}}+\mathbf{J}_{2}\left(\underline{Z}_{\mathrm{W}}+Z_{e}+2 R_{\mathrm{GD}}\right)-\mathbf{J}_{3} R_{\mathrm{GD}}=\mathbf{E}_{\mathrm{WC} 2} \text {; } \\
& -\mathbf{J}_{13} R_{\mathrm{GD}}+\mathbf{J}_{14}\left(\underline{Z}_{\mathrm{W}}+Z_{e}+2 R_{\mathrm{GD}}\right)-\mathbf{J}_{15} R_{\mathrm{GD}}=\mathbf{E}_{\mathrm{WC} 2} ; \\
& -\mathbf{J}_{14} R_{\mathrm{GD}}+\mathbf{J}_{15}\left(\underline{Z}_{\mathrm{W}}+Z_{e}+R_{\mathrm{GD}}+\underline{Z}_{\mathrm{NE}}\right)=\mathbf{E}_{\mathrm{WC} 2} \text {. }
\end{aligned}
$$

The data for system of equations (5):

$\underline{Z}_{\mathrm{W}}+Z_{e}+R_{\mathrm{GD} \Pi}+R_{\mathrm{GD}}=10.580+\mathrm{j} 0.2375$ Ohm; $\underline{Z}_{\mathrm{W}}+Z_{e}+2 R_{\mathrm{GD}}=20.080+\mathrm{j} 0.2375 \mathrm{Ohm} ; \underline{Z}_{\mathrm{NE}}=1.245+$ j0.809 Ohm; $\underline{Z}_{\mathrm{W}}+Z_{e}+R_{\mathrm{GD}}+\underline{Z}_{\mathrm{NE}}=11.334+\mathrm{j} 1.0465$ Ohm; $R_{\mathrm{GDS}}=0.5 \mathrm{Ohm} ; R_{\mathrm{GD}}=10 \mathrm{Ohm}$.

Solving the system (5), we obtain the values of induced in LW currents:

$$
\begin{aligned}
& \mathbf{I}_{\mathrm{w} 1}=4,981 \angle-114.0^{\circ} \mathrm{A} ; \quad \mathbf{I}_{\mathrm{w} 2}=5,178 \angle-114.1^{\circ} \mathrm{A} ; \\
& \mathbf{I}_{\mathrm{w} 3}=5,325 \angle-114.3^{\circ} \mathrm{A} ; \quad \mathbf{I}_{\mathrm{w} 4}=5,424 \angle-114.5^{\circ} \mathrm{A} ; \\
& \mathbf{I}_{\mathrm{w} 5}=5,475 \angle-114.7^{\circ} \mathrm{A} ; \quad \mathbf{I}_{\mathrm{w} 6}=\underline{5,480 \angle-114.9^{\circ} \mathrm{A} ;} \\
& \mathbf{I}_{\mathrm{w} 7}=5,440 \angle-115.1^{\circ} \mathrm{A} ; \quad \mathbf{I}_{\mathrm{w} 8}=5,353 \angle-115.3^{\circ} \mathrm{A} ; \\
& \mathbf{I}_{\mathrm{w} 9}=5,221 \angle-115.6^{\circ} \mathrm{A} ; \quad \mathbf{I}_{\mathrm{w} 10}=5,042 \angle-115.9^{\circ} \mathrm{A} ; \\
& \mathbf{I}_{\mathrm{w} 11}=4,817 \angle-116.6^{\circ} \mathrm{A} ; \quad \mathbf{I}_{\mathrm{w} 12}=4,544 \angle-117.3^{\circ} \mathrm{A} ; \\
& \mathbf{I}_{\mathrm{w} 13}=4,226 \angle-118.7^{\circ} \mathrm{A} ; \quad \mathbf{I}_{\mathrm{w} 14}=3,863 \angle-120.6^{\circ} \mathrm{A} ; \\
& \mathbf{I}_{\mathrm{w} 15}=3,463 \angle-123.9^{\circ} \mathrm{A} .
\end{aligned}
$$

The greatest value of induced in LW current modulus falls in the sixth span, where $I_{\mathrm{wmax}}=I_{\mathrm{w} 6}=5.480 \mathrm{kA}$, and according to table 1 FOLW-sh-1-24(G.652)-18.7/93 $1 \mathrm{~s}$ withstand $18.7 \mathrm{kA}$ SC current, ie, it can operate with a large margin for thermal stability.

There were carried out the calculations of the highest currents $\mathbf{I}_{\mathrm{W} \max }$ under C2 phase SPhSC at $l_{\mathrm{SC} 2}=0.5,1,2$, 3, 4, 5, 7.842 and $10 \mathrm{~km}$ distances from S2 for FOLWsh-1-24(G.652)-18.7/93 and FOLW-c-1-24(G.652)$12 / 94$ (with the greatest differences in nominal radii $r_{\mathrm{wLW}}$ and resistivities $\mathrm{R}_{\mathrm{LW} 0}$ ). 
Table 2 given distances $l_{\mathrm{SC} 2}$ of SC points, number of spans $\mathrm{P}_{\mathrm{K} 3}$, exposed by SC current magnetic field (MF), the values of $\mathrm{C} 2$ phase SC current $\mathbf{I}_{\mathrm{SCC} 2}$ as well as electromotive force $\mathbf{E}_{\mathrm{WC2}}$, induced in FOLW span by current $\mathbf{I}_{\mathrm{SCC} 2}$ MF. Current module histograms $\mathbf{I}_{\mathrm{Wmax}}$ shown in Figure 6.

Table 2. Distances $l_{\mathrm{SC} 2}$, span number $\mathrm{P}_{\mathrm{SC}}$, current value $\mathbf{I}_{\mathrm{SCC} 2}$ and electromotive force $\mathbf{E}_{\mathrm{WC} 2}$ in FOLW span

\begin{tabular}{|c|c|c|c|}
\hline$L_{\mathrm{SC} 2}, \mathrm{~km}$ & $\mathrm{P}_{\mathrm{SC}}$ & $\mathbf{I}_{\mathrm{SCC} 2}, \mathrm{kA}$ & $\mathbf{E}_{\mathrm{wC} 2}, \mathrm{~V}$ \\
\hline 0.5 & 2 & $20.75 \angle 41.8^{\circ}$ & $2,085.6 \angle-56.8^{\circ}$ \\
\hline 1 & 3 & $19.96 \angle 41.6^{\circ}$ & $2,006.2 \angle-57.0^{\circ}$ \\
\hline 2 & 6 & $18.69 \angle 41.0^{\circ}$ & $1,878.6 \angle-57.6^{\circ}$ \\
\hline 3 & 9 & $17.56 \angle 40.4^{\circ}$ & $1,765.0 \angle-58.2^{\circ}$ \\
\hline 4 & 12 & $16.57 \angle 39.9^{\circ}$ & $1,665.5 \angle-58.7^{\circ}$ \\
\hline 5 & 15 & $15.47 \angle 39.1^{\circ}$ & $1,582.1 \angle-59.5^{\circ}$ \\
\hline 7.842 & 24 & $13.60 \angle 38.5^{\circ}$ & $1,367.0 \angle-60.1^{\circ}$ \\
\hline 10 & 31 & $12.42 \angle 37.7^{\circ}$ & $1,248.4 \angle-60.9^{\circ}$ \\
\hline
\end{tabular}

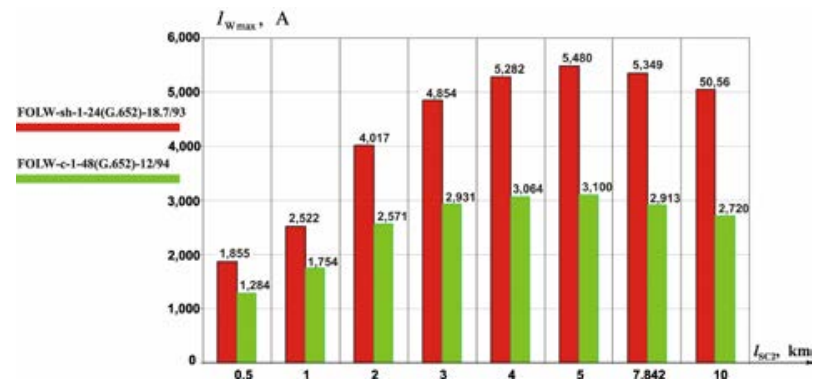

Fig. 6. Current module $\mathbf{I}_{\mathrm{Wmax}}$ change dependence on $l_{\mathrm{SC} 2}$ histogram for FOLW-sh-1-24(G.652)-18.7/93 and FOLW -c-148(G.652)-12/94.

On one side, as the distance $l_{\mathrm{SC} 2}$ increase the number of LW span exposed to $\mathbf{I}_{\mathrm{SCC} 2} \mathrm{SC}$ current rise, each of which adds FOLW longitudinal resistance, GD cross-resistance and longitudinal electromotive force $\mathbf{E}_{\mathrm{wC2}}$, which leads to current module $\mathbf{I}_{\mathrm{Wmax}}$ elevation.

But on another side $l_{\mathrm{SC} 2}$ distance increase leads to SC current module $\mathbf{I}_{\mathrm{SCC} 2}$ decrease, induced by current electromotive force $\mathbf{E}_{\mathrm{WC2}}$ reduce as well as $\mathbf{I}_{\mathrm{Wmax}}$ current value decrease. For considered $220 \mathrm{kV}$ OTL the process of $\mathbf{I}_{\mathrm{W} \max }$ current value increase prevails for distfances from SC point $l_{\mathrm{SC} 2}<5 \mathrm{~km}$, and for distances $l_{\mathrm{SC} 2}>5 \mathrm{~km}$ process of $\mathbf{I}_{\mathrm{SCC} 2}$, current value decrease as well as current decrease prevails. Thus when $l_{\mathrm{SC2}}=5 \mathrm{~km}$ $\mathbf{I}_{\mathrm{w} \max }$ current reaches its greatest value $I_{\mathrm{W} \text { max }}=5480 \mathrm{~A}$ for FOLW -sh-1-24(G.652)-18.7/93 and $I_{\text {T } \max }=3100$ A for FOLW -c-1-24(G.652)-12/94.

\section{Currents in LW under no-loaded mode OTL two self-titled phases SPhSC}

Concider the rare but possible case when in $220 \mathrm{kV}$ OTL at $l_{\mathrm{SC} 2}=5 \mathrm{~km}$ from S2 there are simultanious SC selftitle phases $\mathrm{C} 1$ and $\mathrm{C} 2$ on the earth (see Figure 7).

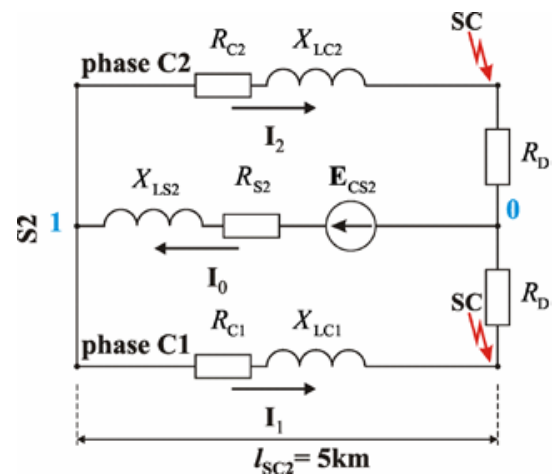

Fig. 7. The scheme of phases C1 and C2 simultanious SC on the earth currents values calculation

Figure 7: $R_{\mathrm{C} 1}=R_{\mathrm{C} 2}=0.356$ Ohm, $X_{\mathrm{LC} 1}=X_{\mathrm{LC} 2}=2.213$ Ohm, $R_{\mathrm{S} 2}=0.841 \mathrm{Ohm}, X_{\mathrm{LS} 2}=5.796 \mathrm{Ohm}, R_{\mathrm{D}}=0.42$ Ohm and $\mathbf{E}_{\mathrm{CS} 2}=127,017 \angle 120^{\circ} \mathrm{V}$.

The scheme contains three branches and two nodes. Entering data of the scheme Fig. 7 in sub "Stationary electric circuit" program «WMRUS», get the current values in the branches:

$$
\begin{aligned}
& \mathbf{I}_{0}=18,194.5 \angle 38.6^{\circ} \mathrm{A} ; \quad \mathbf{I}_{1}=9,097 \cdot 2 \angle 38.6^{\circ} \mathrm{A} ; \\
& \mathbf{I}_{2}=9,097 \cdot 2 \angle 38.6^{\circ} \mathrm{A} .
\end{aligned}
$$

Phase C1 and C2 SC currents are equal: $\mathbf{I}_{\mathrm{SCC} 1}=$ $\mathbf{I}_{\mathrm{SCC} 2}=9,097.2 \angle 38.6^{\circ} \mathrm{A}$.

Phase $\mathrm{C} 1$ and $\mathrm{C} 2$ equivalent height $h_{\mathrm{C} 1}=h_{\mathrm{C} 2}=23.57$ m. LW equivalent height: $h_{\mathrm{W}}=30.94 \mathrm{~m}$. The distance between $\mathrm{LW}$ and $\mathrm{C} 1$ phase by x-axis x: $a_{\mathrm{WC1}}=3.680 \mathrm{~m}$, and between LW C2 phase: $a_{\mathrm{WC} 2}=2.400 \mathrm{~m}$.

Electromotive forces (voltages) $\mathbf{E}_{\mathrm{WC} 1}$ and $\mathbf{E}_{\mathrm{WC2}}$, induced in LW by C1 and C2 phases SPhSC currents determine by equation (3): $\mathbf{E}_{\mathrm{wC} 1}=902.1 \angle-60.1^{\circ} \mathrm{V}$, $\mathbf{E}_{\mathrm{wC} 2}=914.4 \angle-60.0^{\circ} \mathrm{V}$.

Resulting voltage induced in LW by $\mathrm{C} 1$ and $\mathrm{C} 2$ phases SPhSC currents is: $\mathbf{E}_{\mathrm{wC} 2}=\mathbf{E}_{\mathrm{wC} 1}+\mathbf{E}_{\mathrm{wC} 2}=1816.5 \angle-60.0^{\circ}$ $\mathrm{V}$, and it substitute electromotive force (voltage) $\mathbf{E}_{\mathrm{WC2}}$ in equations (5).

Current values in LW calculations are carried out for all of chosen FOLW types. Let us consider, as an example, the case of $220 \mathrm{kV}$ OTL equipped with FOLW -sh-1-24(G.652)-18.7/93. The initial data for the resistances of the system of equations (5) are given earlier and do not change. Substituting in the system of equations (5) the resistance and $\mathbf{E}_{\mathrm{WCE}}$ and solving it, we obtain the values of induced in LW currents:

$$
\begin{array}{ll}
\mathbf{I}_{\mathrm{w} 1}=5,722 \angle-114.5^{\circ} \mathrm{A} ; & \mathbf{I}_{\mathrm{w} 2}=5,948 \angle-114.7^{\circ} \mathrm{A} ; \\
\mathbf{I}_{\mathrm{w} 3}=6,117 \angle-114.8^{\circ} \mathrm{A} ; & \mathbf{I}_{\mathrm{w} 4}=6,231 \angle-115,0^{\circ} \mathrm{A} ; \\
\mathbf{I}_{\mathrm{w} 5}=6,290 \angle-115.2^{\circ} \mathrm{A} ; & \mathbf{I}_{\mathrm{w} 6}=\underline{6,296 \angle-115.4^{\circ} \mathrm{A} ;} \\
\mathbf{I}_{\mathrm{w} 7}=6,249 \angle-114.6 \mathrm{~A} ; & \mathbf{I}_{\mathrm{w} 8}=6,150 \angle-115.8^{\circ} \mathrm{A} ; \\
\mathbf{I}_{\mathrm{w} 9}=5,997 \angle-116.1^{\circ} \mathrm{A} ; & \mathbf{I}_{\mathrm{w} 10}=5,792 \angle-116.4^{\circ} \mathrm{A} ; \\
\mathbf{I}_{\mathrm{w}_{11}}=5,533 \angle-117.0^{\circ} \mathrm{A} ; & \mathbf{I}_{\mathrm{w} 12}=5,220 \angle-117.8^{\circ} \mathrm{A} ; \\
\mathbf{I}_{\mathrm{w}_{13}}=4,854 \angle-119.1^{\circ} \mathrm{A} ; & \mathbf{I}_{\mathrm{w} 14}=4,437 \angle-121.1^{\circ} \mathrm{A} ; \\
\mathbf{I}_{\mathrm{w} 15}=3,978 \angle-124.4^{\circ} \mathrm{A} . &
\end{array}
$$


The greatest value of induced in LW current module is at the 6th span, where $I_{\mathrm{w} 6}=6.296 \mathrm{kA}$, and according to table 1, FOLW-sh-1-24(G.652)-18.7/93 $1 \mathrm{~s}$ withstand the $18.7 \mathrm{kA}$ short-circuit current, i.e can operate with more than a double margin for thermal resistance.

\section{Currents induced in LW by magnetic field of $220 \mathrm{kV}$ OTL, operating in the connected mode, but without power transfer SPhSC}

Figure 8 shows the scheme of calculation the currents in case of $220 \mathrm{kV}$ double-circuit OTL, operating in the connected mode, but without power transfer, C2 phase SPhSC. SC point is located at $5 \mathrm{~km}$ distance from S2.

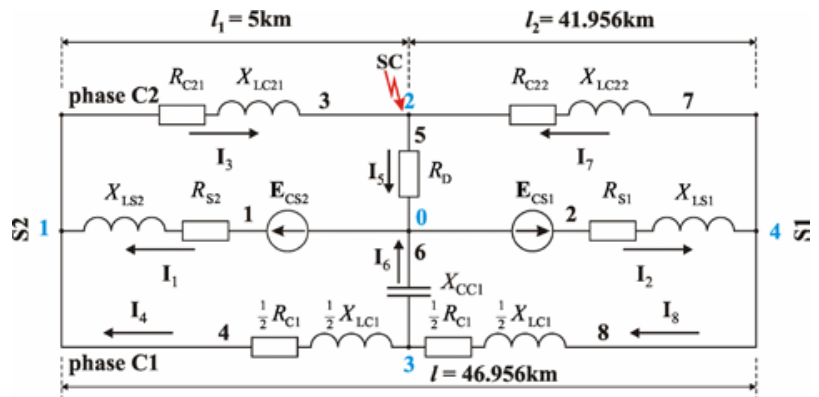

Fig. 8. The scheme of calculation the currents in case of 220 $\mathrm{kV}$ double-circuit OTL, operating in the connected mode, but without power transfer, C2 phase SPhSC

C2 phase $l=46.956 \mathrm{~km}$ length consists of 142 spans and is diveded into two parts: $l_{1}=5 \mathrm{~km}$ from S2 to SC point contains 15 spans, and $l_{2}=41.956 \mathrm{~km}$ from SC point to S1 contains 127 spans. Since the capacitive resistances between phase and SC arc earth of C2 phase both parts are shunted by resistance $R_{D}=0.42 \mathrm{Ohm}$, currents in capacitive resistances (tens of $\mathrm{kOhm}$ ) are neglected. C1 phase is represented by T-shaped replacement circuit. $\mathbf{I}_{3}$ and $\mathbf{I}_{4}$ currents are oppositily directed, $\mathbf{I}_{7}$ and $\mathbf{I}_{8}$ currents are in the same direction, but opposite $\mathbf{I}_{3}$ current.

Figure 8 scheme parameters: $R_{0 \mathrm{ph}}=0.073 \mathrm{Ohm} / \mathrm{km}$, $L_{0 \mathrm{C} 1}=L_{0 \mathrm{C} 2}=0.141 \cdot 10^{-2} \mathrm{H} / \mathrm{km}, C_{0 \mathrm{C} 1}=0.8379 \cdot 10^{-8} \mathrm{~F} / \mathrm{km}$, $R_{\mathrm{C} 21}=R_{0 \mathrm{ph}} l_{1}=0.365 \mathrm{Ohm}, R_{\mathrm{C} 22}=R_{0 \mathrm{ph}} l_{2}=3.063 \mathrm{Ohm}$, $X_{\mathrm{LC} 21}=\omega L_{0 \mathrm{C} 2} l_{1}=2 ., 213 \mathrm{Ohm}, X_{\mathrm{LC} 22}=\omega L_{0 \mathrm{C} 2} l_{2}=18.751$ Ohm, $0.5 X_{\mathrm{LC} 1}=10.392 \mathrm{Ohm}, 0.5 R_{\mathrm{C} 1}=1.714 \mathrm{Ohm}, X_{\mathrm{CC} 1}=$ 8,090.4 Ohm, $\mathbf{E}_{\mathrm{CS} 1}=\mathbf{E}_{\mathrm{CS} 2}=127,017 \angle 120^{\circ} \mathrm{V}$.

On the subroutine "Stationary electric circuit" of the program "WMRUS" we get the values of currents in the branches for C2 phase SPhSC:

$$
\begin{array}{ll}
\mathbf{I}_{1}=14,983 \angle 42.5^{\circ} \mathrm{A} ; & \mathbf{I}_{2}=5,815 \angle 42.0^{\circ} \mathrm{A} ; \\
\mathbf{I}_{3}=16,805 \angle 42.4^{\circ} \mathrm{A} ; & \mathbf{I}_{4}=1,822 \angle 41.8^{\circ} \mathrm{A} ; \\
\mathbf{I}_{5}=20,806 \angle 42.4^{\circ} \mathrm{A} ; & \mathbf{I}_{6}=7.29 \angle-155.6^{\circ} \mathrm{A} ; \\
\mathbf{I}_{7}=4,000 \angle 42.0^{\circ} \mathrm{A} ; & \mathbf{I}_{8}=1,815 \angle 41.8^{\circ} \mathrm{A} .
\end{array}
$$

Figure 9 shows the diagram of the phases $\mathrm{C} 1$ and $\mathrm{C} 2$ with SC currents, combined with the circuit grounded at the ends of wire $\mathrm{W}$ spans.
Figure 9: $R_{\mathrm{GD} 1}=R_{\mathrm{GD}(\mathrm{N}+1)}=R_{\mathrm{GD}}=0.5 \mathrm{Ohm} ; R_{\mathrm{GD} 2}$ $=\ldots=R_{\mathrm{GD} \mathrm{n}}=\ldots=R_{\mathrm{GDN}}=R_{\mathrm{GD}}=10$ Ohm; $\mathbf{E}_{\mathrm{W} \Sigma 1}=\mathbf{E}_{\mathrm{WC} 21}-\mathbf{E}_{\mathrm{WC} 11} ; \mathbf{E}_{\mathrm{W} \Sigma 2}=\mathbf{E}_{\mathrm{WC} 22}+\mathbf{E}_{\mathrm{WC} 12}$.

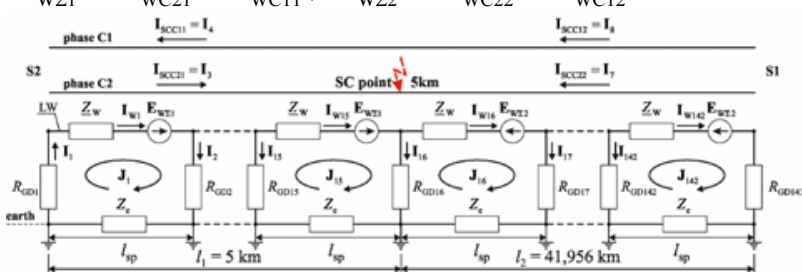

Fig. 9. The diagram of C1 and C2 phases with SC currents, combined with the circuit grounded at the ends of LW spans.

$\mathbf{E}_{\mathrm{WC} 21}$ - voltage in LW from $\mathbf{I}_{3}$ current C2 phase part $l_{1}$. $\mathbf{E}_{\mathrm{WC11}}$ - voltage in LW from $\mathbf{I}_{4}$ current $\mathrm{C} 1$ phase part $l_{1}$ $\mathbf{E}_{\mathrm{WC22}}$ - voltage in LW from $\mathbf{I}_{7}$ current C2 phase part $l_{2}$. $\mathbf{E}_{\mathrm{WC} 12}$ - voltage in LW from $\mathbf{I}_{8}$ current $\mathrm{C} 1$ phase part $l_{2}$. For scheme shown in Figure 9, by the method of contour currents we obtain:

$$
\begin{aligned}
& \mathbf{J}_{1}\left(\underline{Z}_{\mathrm{W}}+Z_{e}+R_{\mathrm{GDS}}+R_{\mathrm{GD}}\right)-\mathbf{J}_{2} R_{\mathrm{GD}}=\mathbf{E}_{\mathrm{W} \Sigma 1} ; \\
& -\mathbf{J}_{1} R_{\mathrm{GD}}+\mathbf{J}_{2}\left(\underline{Z}_{\mathrm{W}}+Z_{e}+2 R_{\mathrm{GD}}\right)-\mathbf{J}_{3} R_{\mathrm{GD}}=\mathbf{E}_{\mathrm{W} \Sigma 2} ; \\
& -\mathbf{J}_{140} R_{\mathrm{GD}}+\mathbf{J}_{141}\left(\underline{Z}_{\mathrm{W}}+Z_{e}+2 R_{\mathrm{GD}}\right)-\mathbf{J}_{142} R_{\mathrm{GD}}=\mathbf{E}_{\mathrm{W} \Sigma 2} ; \\
& -\mathbf{J}_{141} R_{\mathrm{GD}}+\mathbf{J}_{142}\left(\underline{Z}_{\mathrm{W}}+Z_{e}+R_{\mathrm{GD}}+R_{\mathrm{GDS}}\right)=\mathbf{E}_{\mathrm{W} \Sigma 2} \text {. }
\end{aligned}
$$

Voltage (electromotive force) values:

$\mathbf{E}_{\mathrm{WC} 21}=1,689 \angle-56.2^{\circ} \mathrm{V} ; \mathbf{E}_{\mathrm{WC} 11}=180.9 \angle-56.9^{\circ} \mathrm{V}$;

$\mathbf{E}_{\mathrm{WC} 22}=402.0 \angle-56.6^{\circ} \mathrm{V} ; \mathbf{E}_{\mathrm{WC} 12}=180.2 \angle-56.9^{\circ} \mathrm{V}$;

$\mathbf{E}_{W \Sigma 1}=1,508 \angle-56^{\circ} \mathrm{V} ; \quad \mathbf{E}_{\mathrm{W} \Sigma 2}=582 \angle-57^{\circ} \mathrm{V}$.

Resistance values:

$\underline{Z}_{\mathrm{W}}+Z_{\mathrm{e}}+R_{\mathrm{GDS}}+R_{\mathrm{GD}}=10.580+\mathrm{j} 0.2375 \mathrm{Ohm} ;$

$\underline{Z}_{\mathrm{W}}+Z_{\mathrm{e}}+2 R_{\mathrm{GD}}=20.080+\mathrm{j} 0.2375 \mathrm{Ohm}$;

$\underline{Z}_{\mathrm{W}}+Z_{\mathrm{e}}+R_{\mathrm{GD}}+\underline{Z}_{\mathrm{NE}}=11.334+\mathrm{j} 1.0465 \mathrm{Ohm}$;

$\underline{Z}_{\mathrm{NE}}=1.245+\mathrm{j} 0.809 \mathrm{Ohm}$;

$R_{\mathrm{GDS}}=0.5 \mathrm{Ohm} ; R_{\mathrm{GD}}=10 \mathrm{Ohm}$.

Solving the system of equations (6), we obtain the currents in LW $\mathbf{I}_{\mathrm{Wi}}=\mathbf{J}_{\mathrm{i}}$. Current $\mathbf{I}_{\mathrm{Wi}}$ modules distribution along OTL is shown in Figure 10.

$220 \mathrm{kV}$ OTL operating in the connected mode at both ends, but without power transfer SPhSC at $5 \mathrm{~km}$ distance from S2 leads to induce in LW current with maximal module value $\mathrm{I}_{\mathrm{Wmax}}=5,152 \mathrm{~A}$ in 5th span, but it is less than $\mathrm{I}_{\mathrm{Wmax}}=5,480 \mathrm{~A}$ under SPhSC in the same OTL in no-load mode.

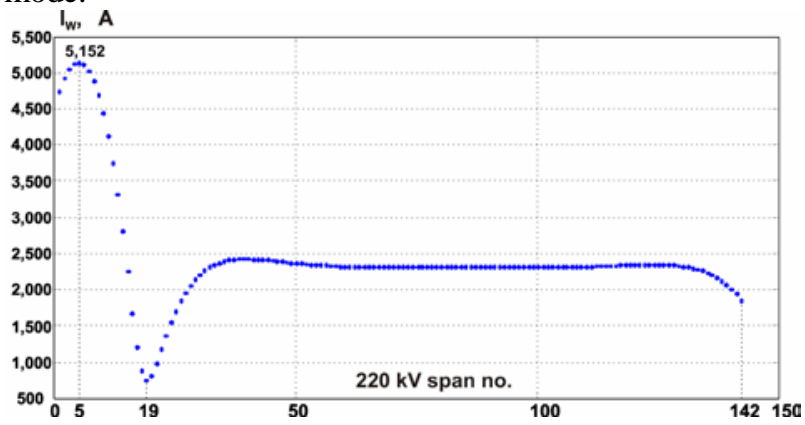

Fig. 10. Current modules $\mathbf{I}_{\mathrm{Wi}}$ distribution along $220 \mathrm{kV}$ OTL 


\section{Simultaneous determination of SC currents and induced in LW currents}

The considered methods for calculating the currents induced in $\mathrm{LW}$ by $\mathrm{SPhSC}$ current MF do not take into account SC current itself passage in LW from SC point to the phase electromotive force (voltage) in the line beginning, for example $\mathbf{E}_{\mathrm{C} 2}$. Figure 11 shows the scheme of simultaneous SC current at $5 \mathrm{~km}$ from S2 distance and currents in LW determination for $220 \mathrm{kV}$ OTL in noloaded mode. Figure 11: $R_{\mathrm{C} 2}+\mathrm{j} X_{\mathrm{LC} 2}-$ phase C2 wire in single span resistance-inductive reactance; $R_{\mathrm{W}}+$ $\mathrm{j} X_{\mathrm{LW}}$ - wire LW in single span resistance-inductive reactance; $Z_{\mathrm{e}}$ - resistance to reverse current in the ground for a single span; $\underline{Z}_{\mathrm{WC} 2}$ - mutual inductive reactance C2 phase and LW in span, obtained by equation (2); $R_{\mathrm{S} 2}$ $+\mathrm{j} X_{\mathrm{LS} 2}-$ network resistance for $\mathrm{S} 2 ; \underline{Z}_{\mathrm{NE}}$ - resulting resistance after wire passive two-terminal network folding withpeзультирующее сопротивление после сворачивания пассивных двухполюсников троса with step $l_{\mathrm{sp}}=0.33 \mathrm{~km} ; R_{\mathrm{GDS}}=0.5 \mathrm{Ohm}-\mathrm{S} \mathrm{GD}$ resistance; $R_{\mathrm{GD}}=10 \mathrm{Ohm}$ - OTL tower GD resistance; $R_{\mathrm{D}}=0.42 \mathrm{Ohm}-\mathrm{SC}$ arc resistance; $\mathbf{E}_{\mathrm{C} 2}=$ $127,017 \angle 120^{\circ} \mathrm{V}-\mathrm{C} 2$ phase electromotive force.

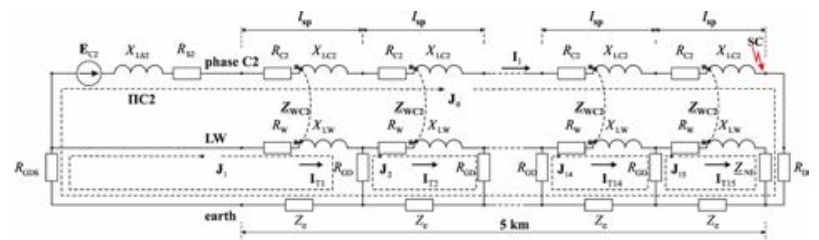

Fig. 11. The scheme of C2 phase SC current and induced in LW current determination

According Figure 11 scheme for single span of OTL and LW FOLW-sh-1-24(G.652)-18.7/93: $\quad R_{\mathrm{C} 2}+\mathrm{j} X_{\mathrm{LC} 2}=$ $0.02433+\mathrm{j} 0.23388 \mathrm{Ohm} ; R_{\mathrm{W}}+\mathrm{j} X_{\mathrm{LW}}=0.0667+\mathrm{j} 0.2422$ Ohm; $Z_{\mathrm{e}}=0.01533 \mathrm{Ohm} ; \mathrm{Z}_{\mathrm{WC2}}=0.015+\mathrm{j} 0.101 \mathrm{Ohm} ; R_{\mathrm{S} 2}$ $+\mathrm{j} X_{\mathrm{LS} 2}=0.841+\mathrm{j} 5.796 \mathrm{Ohm} ; \underline{Z}_{\mathrm{NE}}=1.257+\mathrm{j} 0.816 \mathrm{Ohm}$; $R_{\mathrm{GDS}}=0.5 \mathrm{Ohm} ; R_{\mathrm{GD}}=10 \mathrm{Ohm} ; R_{\mathrm{D}}=0.42 \mathrm{Ohm}$.

Let us formulate a system of equations by the method of contour currents:

$$
\left.\begin{array}{l}
\mathbf{J}_{0}\left[R_{\mathrm{S}}+j X_{\mathrm{LS}}+15\left(R_{\mathrm{C} 2}+j X_{\mathrm{LC} 2}+Z_{e}\right)+R_{\mathrm{D}}+R_{\mathrm{GDS}}\right]+ \\
\quad+\mathbf{J}_{1}\left(R_{\mathrm{GDS}}+Z_{\mathrm{e}}+\underline{Z}_{\mathrm{WC} 2}\right)+\mathbf{J}_{2}\left(Z_{\mathrm{e}}+\underline{Z}_{\mathrm{WC} 2}\right)+\ldots .+\mathbf{J}_{15}\left(Z_{\mathrm{e}}+\underline{Z}_{\mathrm{WC} 2}\right)=\mathbf{E}_{\mathrm{C} 2} ; \\
\mathbf{J}_{0}\left(R_{\mathrm{GDS}}+Z_{\mathrm{e}}+\underline{Z}_{\mathrm{WC} 2}\right)+\mathbf{J}_{1}\left(R_{\mathrm{W}}+j X_{\mathrm{LW}}+R_{\mathrm{GD}}+Z_{e}+R_{\mathrm{GDS}}\right)-\mathbf{J}_{2} R_{\mathrm{GD}}=0 \\
\mathbf{J}_{0}\left(Z_{e}+\underline{Z}_{\mathrm{WC} 2}\right)-\mathbf{J}_{1} R_{\mathrm{GD}}+\mathbf{J}_{2}\left(R_{\mathrm{W}}+j X_{\mathrm{LW}}+2 R_{\mathrm{GD}}+Z_{e}\right)-\mathbf{J}_{3} R_{\mathrm{GD}}=0 \\
\cdots \\
\mathbf{J}_{0}\left(Z_{e}+\underline{Z}_{\mathrm{WC} 2}\right)+0+\ldots+0-\mathbf{J}_{13} R_{\mathrm{GD}}+\mathbf{J}_{14}\left(R_{\mathrm{W}}+j X_{\mathrm{LW}}+2 R_{\mathrm{GD}}+Z_{e}\right)-\mathbf{J}_{15} R_{3 \mathrm{Y}}=0 \\
\mathbf{J}_{0}\left(Z_{e}+\underline{Z}_{\mathrm{WC} 2}\right)+0+\ldots+0-\mathbf{J}_{14} R_{\mathrm{GD}}+\mathbf{J}_{15}\left(R_{\mathrm{W}}+j X_{\mathrm{LW}}+R_{\mathrm{GD}}+Z_{e}+\underline{Z}_{\mathrm{NE}}\right)=0 .
\end{array}\right\}
$$

Solving the system of equations (7), we obtain the values of SPhSC currents as well as currents in LW spans:

$$
\begin{array}{ll}
\mathbf{I}_{1}=\mathbf{I}_{\mathrm{K} 3}=14,098 \angle 43.5^{\circ} \mathrm{A} ; & \mathbf{I}_{\mathrm{w} 1}=\underline{6,876 \angle-133.6^{\circ} \mathrm{A}} \\
\mathbf{I}_{\mathrm{w} 2}=6,544 \angle-133.1^{\circ} \mathrm{A} ; & \mathbf{I}_{\mathrm{w} 3}=6,237 \angle-132.1^{\circ} \mathrm{A} ; \\
\mathbf{I}_{\mathrm{W} 4}=5,950 \angle-131.4^{\circ} \mathrm{A} ; & \mathbf{I}_{\mathrm{w} 5}=5,679 \angle-130.3^{\circ} \mathrm{A} ; \\
\mathbf{I}_{\mathrm{w} 6}=5,421 \angle-129.2^{\circ} \mathrm{A} ; & \mathbf{I}_{\mathrm{w} 7}=5,169 \angle-128.0^{\circ} \mathrm{A} ; \\
\mathbf{I}_{\mathrm{w} 8}=4,920 \angle-126.9^{\circ} \mathrm{A} ; & \mathbf{I}_{\mathrm{w} 9}=4,668 \angle-125.8^{\circ} \mathrm{A} ; \\
\mathbf{I}_{\mathrm{w} 10}=4,40 \angle-124.9^{\circ} \mathrm{A} ; & \mathbf{I}_{\mathrm{w} 11}=4,135 \angle-124.3^{\circ} \mathrm{A} ;
\end{array}
$$

$\mathbf{I}_{\mathrm{w} 12}=3,845 \angle-124.1^{\circ} \mathrm{A} ; \quad \mathbf{I}_{\mathrm{w} 13}=3,535 \angle-124.6^{\circ} \mathrm{A} ;$ $\mathbf{I}_{\mathrm{w} 14}=3,204 \angle-126.0^{\circ} \mathrm{A} ; \quad \mathbf{I}_{\mathrm{w} 15}=2,858 \angle-128.9^{\circ} \mathrm{A}$. Maximin value of current in LW module is in the $1 \mathrm{st}$ span, where $I_{\mathrm{w} 1}=6.876 \mathrm{kA}$. SPhSC current passes in $\mathrm{LW}$ trough even $R_{\mathrm{GD}}$ from SC point to electromotive force $\mathbf{E}_{\mathrm{C} 2}$ and by summation become maximal in 1st OTL span. According table 1 data, FOLW-sh-124(G.652)-18.7/93 within $1 \mathrm{~s}$ withstand $18.7 \mathrm{kA}$ SC current, i.e can be operated with margin $\Delta \mathrm{I}=11.8 \mathrm{kA}$ for heat resistance. SPhSC currents and currents induced in LW are calculated by the method of simultaneous determination for all of chosen FOLW types.

\section{Conclusion}

The currents induced by SPhSC currents in LW are maximal and most accurate in case of its simultaneous determination. Table 3 gives the results of the calculation by simultaneous method of current modules: SPhSC currents - $\mathbf{I}_{\mathrm{SCC} 2}$, maximal currents in LW $-\mathbf{I}_{\mathrm{Wmax}}$, allowable currents of heat resistance - $\mathbf{I}_{\mathrm{SCLW}}$ and margin $\Delta \mathrm{I}$ by heat resistance current for all chosen FOLW types.

Table 3. The values of calculated by simultanious calculation method $\mathrm{I}_{\mathrm{SCC} 2}, \mathrm{I}_{\mathrm{Wmax}}, \mathrm{I}_{\mathrm{SCLW}}$ and $\Delta \mathrm{I}$

\begin{tabular}{|c|c|c|c|c|}
\hline FOLW brand & $\begin{array}{c}\mathrm{I}_{\mathrm{SCC} 2}, \\
\mathrm{kA}\end{array}$ & $\begin{array}{c}\mathrm{I}_{\mathrm{Wmax}}, \\
\mathrm{kA}\end{array}$ & $\begin{array}{c}\mathrm{I}_{\mathrm{SCLW}}, \\
\mathrm{kA}\end{array}$ & $\begin{array}{c}\Delta \mathrm{I}, \\
\mathrm{kA}\end{array}$ \\
\hline $\begin{array}{c}\text { FOLW-sh-1- } \\
\text { 24(G.652)-18.7/93 }\end{array}$ & 14.098 & 6.876 & 18.7 & 11.8 \\
\hline $\begin{array}{c}\text { FOLW - sh -1- } \\
\text { 16(G.652)-14.7/61 }\end{array}$ & 14.023 & 6.301 & 11.5 & 5.18 \\
\hline $\begin{array}{c}\text { FOLW - sh -1- } \\
\text { 24(G.652)-13.1/54 }\end{array}$ & 13.957 & 5.846 & 8.9 & 3.05 \\
\hline $\begin{array}{c}\text { FOLW -c-1- } \\
\text { 48(G.652)-12/94 }\end{array}$ & 13.669 & 3.993 & 5.6 & 1.61 \\
\hline
\end{tabular}

\section{Reference}

1. M.V. Kostenko, L.S. Perelman, Yu.P. Shkarin Wave processes and electrical disturbances in multi-wire high-voltage lines. Energy. M., 272, (1973).

2. G.N. Tsitsikjan Electromagnetic compatibility in power industry. ELMOR. St-Petersburg, 184, (2007).

3. Guidelines for the calculation of short-circuit currents and the selection of electrical equipment. G15334.0-20.527-98. Energia. M, 83, (1998).

4. M.Sh. Misrikhanov, Yu.A.Iostson, N.B.Rubtsova, Computer program "Electromagnetic parameters of overhead transmission lines № 2006613744, 27.10.2006.

5. A.Yu. Tokarskiy, N.B.Rubtsova Distribution of voltage induced by parallel transmission line along dead and grounded line. Safety in the Technosphere, 4 (JuneJuly), 32-38, (2015). 